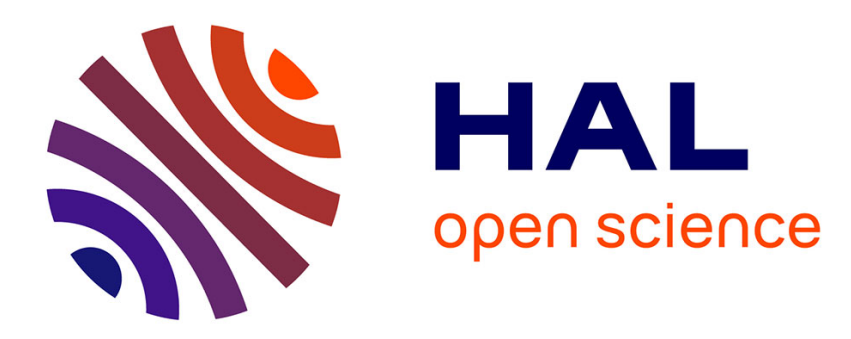

\title{
Anelastic Relaxation of Point Defects in Cubic Crystals
}

\author{
M. Weller
}

\section{To cite this version:}

M. Weller. Anelastic Relaxation of Point Defects in Cubic Crystals. Journal de Physique IV Proceedings, 1996, 06 (C8), pp.C8-63-C8-72. 10.1051/jp4:1996812 . jpa-00254550

\section{HAL Id: jpa-00254550 https://hal.science/jpa-00254550}

Submitted on 1 Jan 1996

HAL is a multi-disciplinary open access archive for the deposit and dissemination of scientific research documents, whether they are published or not. The documents may come from teaching and research institutions in France or abroad, or from public or private research centers.
L'archive ouverte pluridisciplinaire HAL, est destinée au dépôt et à la diffusion de documents scientifiques de niveau recherche, publiés ou non, émanant des établissements d'enseignement et de recherche français ou étrangers, des laboratoires publics ou privés. 


\title{
Anelastic Relaxation of Point Defects in Cubic Crystals
}

\author{
M. Weller
}

\author{
Max-Planck-Institut für Metallforschung, Institut für Werkstoffwissenschaft, Seestrasse 92, \\ 70174 Stuttgart, Germany
}

\begin{abstract}
Point defects in solids can give rise to anelastic relaxation provided that the defects behave as elastic dipoles. Experiments with single crystals give information on the atomic configuration of the point defects. Measurements of the orientation dependence of the relaxation strength allow determination of the defect symmetry and the dipole shape factor $\delta \lambda=\left|\lambda_{1}-\lambda_{2}\right|$. This is demonstrated for two examples: (i) The Snoek relaxation of $O$ and $\mathrm{N}$ in $\mathrm{Nb}$ and Ta single crystals: The $\delta \lambda$ values for $\mathrm{O}$ and $\mathrm{N}$ are in the range of 0.6 to 0.7 . The tetragonal defect symmetry is confirmed by experiments on $\mathrm{Nb}-\mathrm{O}$ crystals with various orientations. (ii) Defects in cubic, $\mathrm{Y}_{2} \mathrm{O}_{3}-$ or $\mathrm{CaO}$-stabilized $\mathrm{ZrO}_{2}$ : The oxygen vacancies created for charge compensation are associated with dopant cations thus forming elastic (and electric) dipoles. The dipoles exhibit trigonal symmetry.
\end{abstract}

\section{THEORETICAL BACKGROUND}

Point defects in solids can give rise to anelastic relaxation provided that the defects behave as elastic dipoles. Elastic dipoles represent atomic defects that produce an anisotropic local distortion of the crystal lattice. Application of elastic stress, as, e.g., in mechanical oscillations, leads to thermally activated reorientation of the dipoles, which manifests itself by the appearance of mechanical loss peaks. The most prominent example is the Snoek effect of heavy interstitial foreign atoms (C, N, O) in bcc metals, which was originally discovered by Snoek [1] in iron containing carbon and nitrogen.

The occurence of anelastic relaxation due to the presence of point defects is based on the following considerations $[2,3,4]$ :

(i) The defect exhibits a symmetry lower than that of the host crystal.

(ii) The introduction of the defect produces anisotropic local elastic distortion which can be characterized by a second rank tensor, the $\lambda$-tensor. The tensor describes the strain of a crystal by introduction of unit concentration of defects. The tensor can be expressed in the following form:

$$
\lambda=\left(\begin{array}{ccc}
\lambda_{1} & 0 & 0 \\
0 & \lambda_{2} & 0 \\
0 & 0 & \lambda_{3}
\end{array}\right) .
$$

The principal values $\lambda_{1}, \lambda_{2}$, and $\lambda_{3}$ represent the half axes of a strain ellipsoid which characterizes the local deformation around the defect.

The dipole tensor exhibits several distinguishable defect orientations $n_{t}$. The condition for anelastic relaxation is expressed by $n_{t}>1$. In an applied external stress field, the various orientations of the dipoles exhibit different energy. This leads to a statistical redistribution of the dipoles with preferred transitions to the lower energy levels.

(iii) When the redistribution process is characterized by a relaxation $\tau$, anelastic relaxation of point defects can be described in the ideal (dilute) case by a Debye peak

$$
Q^{-1}=\Delta \frac{\omega \tau}{1+(\omega \tau)^{2}}
$$


centred at $\omega \tau=1$ with the height $\mathrm{Q}^{-1}=\Delta / 2$. The relaxation time $\tau$ is determined by the kinetics of point defect reorientation. Since in most cases reorientation occurs by thermally activated jumps, the relaxation rate $\tau^{-1}$ obeys an Arrhenius equation

$$
\tau^{-1}=\tau_{\infty}^{-1} \exp (-\mathrm{H} / \mathrm{kT})
$$

where $H=$ activation enthalpy and $k=$ Boltzmann's constant. The pre-exponential factor $\tau_{\infty}{ }^{-1}$ is related to atomic jump rates inherent to the specific defect mechanisms which have to be established in each case. The relaxation strength $\Delta$ describes the magnitude of relaxation which follows, by application of Boltzmann statistics, from the splitting of the energy levels for various orientations of the dipoles by the external elastic field.

The selection rules for anelastic relaxation $[2,3]$ specify which type of defect (i.e., of which symmetry) can give rise to which type of relaxation, as well as the number of relaxations in a specific host crystal. In cubic crystals, to which we restrict in the following, tetragonal and trigonal defects exhibit the highest symmetry and anelastic relaxation is characterized by a single relaxation time $\tau$. The relaxation strength depends on the defect symmetry and the crystal orientation.

Table 1. Orientation dependence of the relaxation amplitudes $\delta E^{-1}(\Gamma)$ and $\delta G^{-1}(\Gamma)$ for various defect symmetries in cubic crystals.

\begin{tabular}{l|ll|ll}
\hline & \multicolumn{2}{|c|}{ FIEXURE } & \multicolumn{2}{c}{ TORSION } \\
\hline Relax. Strength & $\Delta=2 \mathrm{Q}^{-1} \mathrm{~m} \equiv \delta \mathrm{E}^{-1} / \mathrm{E}^{-1}$ & (Ia) & $\Delta=2 \mathrm{Q}_{\mathrm{m}}^{-1} \equiv \delta \mathrm{G}^{-1} / \mathrm{G}^{-1}$ & (Ib) \\
\hline Elastic Compliance & $\mathrm{E}^{-1}=\mathrm{s}_{11}-2\left(\mathrm{~s}_{11}-\mathrm{s}_{12}-\mathrm{s}_{44} / 2\right) \Gamma$ & (IIa) & $\mathrm{G}^{-1}=\mathrm{s}_{44}+4\left(\mathrm{~s}_{11}-\mathrm{s}_{12}-\mathrm{s}_{44} / 2\right) \Gamma \quad$ (IIb) \\
\hline Relax. Amplitude & $\delta \mathrm{E}^{-1}=\Delta \cdot \mathrm{E}^{-1}$ & (IIIa) & $\delta \mathrm{G}^{-1}=\Delta \cdot \mathrm{G}^{-1}$ & (IIIb) \\
\hline
\end{tabular}

Relaxation Amplitudes

\begin{tabular}{|c|c|c|c|c|}
\hline Defect Symmetry & \multicolumn{2}{|l|}{$\delta \mathrm{E}^{-1}$} & \multicolumn{2}{|l|}{$\delta \mathrm{G}^{-1}$} \\
\hline \multirow[t]{2}{*}{$\begin{array}{l}\text { Tetragonal } \\
{[100]}\end{array}$} & $\begin{array}{l}\frac{2}{3} \delta\left(\mathrm{s}_{11}-\mathrm{s}_{12}\right) \mathrm{F}(\Gamma)= \\
\frac{2}{9} \frac{\mathrm{c}_{\mathrm{o}} \mathrm{v}_{\mathrm{o}}}{\mathrm{kT}}\left(\lambda_{1}-\lambda_{2}\right)^{2} \mathrm{~F}(\Gamma)\end{array}$ & (IVa) & $\begin{array}{c}4 \delta\left(s_{11}-s_{12}\right) F(\Gamma)= \\
\frac{4}{3} \frac{c_{0} v_{0}}{k T}\left(\lambda_{1}-\lambda_{2}\right)^{2} F(\Gamma)\end{array}$ & (IVb) \\
\hline & $F(\Gamma)=1-3 \Gamma$ & & $F(\Gamma)=\Gamma$ & \\
\hline $\begin{array}{l}\text { Trigonal } \\
\text { [111] }\end{array}$ & $\begin{array}{l}\delta s_{44} \cdot F(\Gamma)= \\
\frac{4}{9} \frac{c_{o} v_{o}}{k T}\left(\lambda_{1}-\lambda_{2}\right)^{2} F(\Gamma)\end{array}$ & $(\mathrm{Va})$ & $\begin{array}{l}\delta s_{44} \cdot F(\Gamma)= \\
\frac{4}{9} \frac{c_{0} v_{0}}{k T}\left(\lambda_{1}-\lambda_{2}\right)^{2} F(\Gamma)\end{array}$ & (Vb) \\
\hline & $\mathrm{F}(\Gamma)=\Gamma$ & & $F(\Gamma)=1-2 \Gamma$ & \\
\hline
\end{tabular}

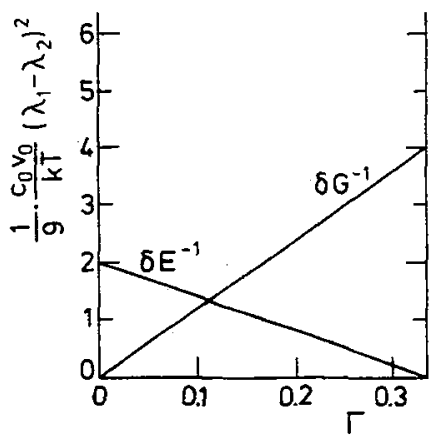

a) tetragonal

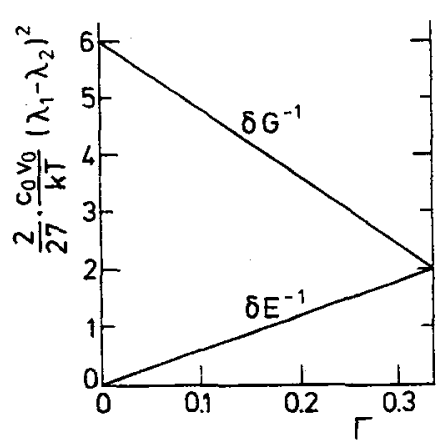

b) trigonal

Figure 1: Variation of the relaxation amplitudes $\delta \mathrm{E}^{-1}$ and $\delta \mathrm{G}^{-1}$ with the orientation parameter $\Gamma$ for tetragonal (a) and trigonal (b) defect symmetry. 
Table 1 gives a compilation of the equations for tetragonal and trigonal defects in a cubic single crystal for flexural and torsional oscillations. The crystal orientation is defined by the orientation parameter

$$
\Gamma=\cos ^{2} \alpha \cos ^{2} \beta+\cos ^{2} \beta \cos ^{2} \gamma+\cos ^{2} \gamma \cos ^{2} \alpha
$$

where $\alpha, \beta, \gamma=$ the angles between the longitudinal stress axis and cube axes, $c_{0}$ is the concentration of dipoles and $v_{0}$ is the molecular volume. The two cases of flexural and torsional stress have to be distinguished. The relaxation strength $\Delta$, which is defined as the ratio $\delta \mathrm{E}^{-1} / \mathrm{E}^{-1}$ or $\delta \mathrm{G}^{-1} / \mathrm{G}^{-1}$, respectively (eqs. Ia, b), depends in two ways on the crystal orientation: (i) The elastic compliances of Young's and torsional modulus $\mathrm{E}^{-1}$ and $\mathrm{G}^{-1}$ are anisotropic, depending on $\Gamma$ (eqs. IIa, b) (elastic anisotropy). (ii) The relaxation amplitudes $\delta \mathrm{E}^{-1}$ and $\delta \mathrm{G}^{-1}$ vary with the crystal orientation (anelastic anisotropy). The variation of the relaxation amplitudes with orientation, $\delta \mathrm{E}^{-1}(\Gamma), \delta \mathrm{G}^{-1}(\Gamma)$, is represented by linear functions $\mathrm{F}(\Gamma)$ (eqs. IV and V) which are calculated from the relaxation of the compliance constants, $\delta\left(s_{11}-s_{12}\right)$ and $\delta s_{44}$, as follows. For tetragonal defects (dipoles), the theory of anelastic relaxation $[2,3]$ gives $\delta s_{44}=0$ and

$$
\delta\left(\mathrm{s}_{11}-\mathrm{s}_{12}\right)=\left(\mathrm{c}_{0} \mathrm{v}_{0} / 3 \mathrm{kT}\right)\left(\lambda_{1}-\lambda_{2}\right)^{2}
$$

(ref. [2], eq. 6.10). For trigonal defects, we have, on the opposite, $\delta\left(s_{11}-s_{12}\right)=0$ and

$$
\delta \mathrm{s}_{44}=\left(\mathrm{c}_{0} \mathrm{v}_{0} / 9 \mathrm{kT}\right)\left(\lambda_{1}-\lambda_{2}\right)^{2} \text {. }
$$

The relaxation amplitudes $\delta \mathrm{E}^{-1}$ and $\delta \mathrm{G}^{-1}$ obey the same equations as the unrelaxed quantities, $\mathrm{E}^{-1}$ and $\mathrm{G}^{-1}$ in eqs. IIa, b [3], e.g. $\delta E^{-1}=\delta s_{11}-2\left[\delta\left(s_{11}-s_{12}\right)-\frac{1}{2} \delta s_{44}\right] \Gamma$. Equations IVa, b and $V a, b$ are then obtained by using the identity $s_{11}=\frac{1}{3}\left[\left(s_{11}+2 s_{12}\right)+2\left(s_{11}-s_{12}\right)\right]$ from which follows $\delta s_{11}=\frac{2}{3} \delta\left(s_{11}-s_{12}\right)$ since $\delta\left(s_{11}\right.$ $\left.+2 s_{12}\right)=0 .\left(s_{11}+2 s_{12}\right)$ represents a compliance of type I (bulk compressibility), which cannot undergo anelastic relaxation if defect reactions are excluded [3]. The linear functions $F(\Gamma)$ for the orientation dependence of the relaxation amplitudes in Table 1 are plotted in Fig. 1a for a tetragonal and in Fig. 1b for a trigonal defect. Fig. 1 demonstrates that measurements of the relaxation amplitudes in single crystals of different orientations allow one to conclude on the symmetry of the defects.

In the following, we present two examples for point defect relaxations in cubic crystals which represent recent experimental work from our institute: the Snoek relaxation in bcc metals, with applications on interstitial diffusion and trace analysis, and defects in cubic stabilized $\mathrm{ZrO}_{2}$.

\section{SNOEK RELAXATION OF INTERSTITIALS IN BCC METALS}

\subsection{Relaxation time}

Heavy interstitial atoms, such as $\mathrm{O}, \mathrm{N}$, or $\mathrm{C}$, in bcc metals induce elastic dipoles with tetragonal symmetry. The stress-induced reorientation of the dipoles is the elementary step of interstitial diffusion. Two types of lattice sites are conceivable for interstitial atoms in bcc metals: octahedral $(0)$ and tetrahedral $(t)$ sites $[3,4]$ as shown in Figs. $2 a$ and $2 b$. The relaxation time $\tau$ is related to the jump rate $w$ between specific neighbouring sites, e.g. $1 \rightarrow 2$, which leads to reorientation. For both o and $t$ sites the relaxation rate $\tau^{-1}$ is given by

$$
\tau^{-1}=6 w .
$$

However, as shown in Figs. $2 a$ and $2 b$, the jump distance between octahedral and tetrahedral sites is different. For o-o jumps it is $a_{0} / 2$ and for $t-t$ jumps $a_{0} / 2 \sqrt{2}$. Thus, the interstitial diffusion coefficients $D^{\circ}$ and $D^{t}$ differ by a factor of 2 :

$$
\begin{aligned}
& D^{\alpha}=a_{0}^{2} / 36 \tau=\left(a_{0}^{2} / 36 \tau_{\infty}\right) \exp (-H / k T) \\
& D^{t}=a_{0}^{2} / 72 \tau=\left(a_{0}^{2} / 72 \tau_{\infty}\right) \exp (-H / k T)
\end{aligned}
$$

Table 2 gives a list of recent values of the relaxation for $\mathrm{H}$ and $\tau_{\infty}{ }^{-1}$ for several combinations of bcc metal and interstitial. Furthermore, the peak temperatures $T_{m}$ for a measuring frequency of $f_{m}=1 \mathrm{~Hz}$ are 

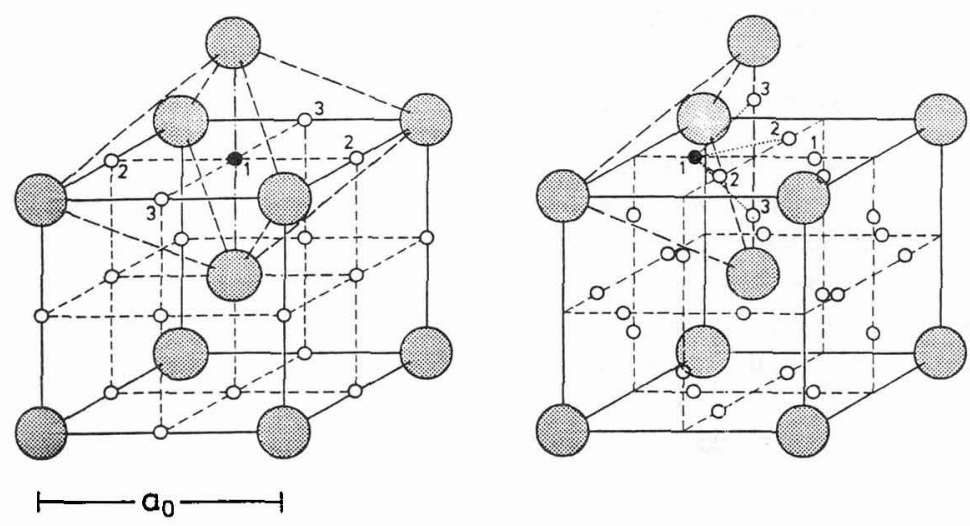

Figure 2: Atomic model of the Snoek Relaxation in bcc metals. (a) Octahedral and (b) tetrahedral interstitial sites.

\begin{tabular}{|c|c|c|c|c|}
\hline & $\mathrm{H}, \mathrm{eV}$ & $\tau_{\infty}^{1}, 10^{14} \mathrm{~s}^{-1}$ & $T_{\mathrm{m}}, \mathrm{I}(\mathrm{f}=1 \mathrm{~Hz})$ & ret: \\
\hline$\overline{\mathrm{Fe}-\mathrm{N}}$ & $0.82 \pm 0.01$ & $4.2 \pm 2$ & 300 & {$[8,10]$} \\
\hline $\mathrm{Fe}-\mathrm{C}$ & $0.87 \pm 0.01$ & $5.3 \pm 2$ & 314 & {$[8,10]$} \\
\hline $\mathrm{Nb}-\mathrm{O}$ & $1.15_{4} \pm 0.01$ & $3.7_{7} \pm 0.8$ & 422 & [5] \\
\hline $\mathrm{Nb}-\mathrm{N}$ & $1.57_{5} \pm 0.02$ & $8.2_{0} \pm 0.8$ & 562 & [5] \\
\hline $\mathrm{Nb}-\mathrm{C}$ & 1.43 & & $514 \pm 2$ & {$[6,7]$} \\
\hline $\mathrm{Ta} a-\mathrm{O}$ & $1.10_{5} \pm 0.01$ & $1.17 \pm 2.5$ & 420 & [5] \\
\hline $\mathrm{Ta}-\mathrm{N}$ & $1.66_{s} \pm 0.02$ & $2.7_{s} \pm 2$ & 615 & [5] \\
\hline $\mathrm{Ta}-\mathrm{C}$ & 1.67 & & $626 \pm 2$ & {$[6,7]$} \\
\hline Mo-N & 1.3 & 0.9 & 498 & [29] \\
\hline$\overline{\mathrm{Cr}-\mathrm{N}}$ & 1.19 & 7 & 429 & [30] \\
\hline $\mathrm{V}-\mathrm{O}$ & 1.29 & 10 & 458 & [31] \\
\hline $\mathrm{V}-\mathrm{N}$ & 1.57 & 19.6 & 544 & [31] \\
\hline
\end{tabular}

Table 2: Snoek relaxation parameters for several combinations of bcc metal and interstitial.

given. $T_{m}$ is obtained from the equation $T_{m}=H / k \cdot \ln \left(2 \pi f_{m} \tau_{\infty}\right)$. (see also [5-9]). To obtain reliable values of the relaxation parameters, as listed in Table 2, measurements over a large range of relaxation times have to be carried out. This is demonstrated in Figs. $3 \mathrm{a}$ and $3 \mathrm{~b}$ for measurements of the Snoek effect of $\mathrm{C}$ and $\mathrm{N}$ in $\alpha-\mathrm{Fe}$. The experimental data for Fe-C (600 at.ppm) and $\mathrm{Fe}-\mathrm{N}$ ( 600 at.ppm) were obtained from internal friction measurements with the same specimen by combining low frequency $\left(10^{-3} \mathrm{~Hz}\right)$ forced vibration, torsion pendulum $(1 \mathrm{~Hz})$ and $\mathrm{kHz}$-measurements [10]. The $\mathrm{H}$ and $\tau_{\infty}{ }^{-1}$ values in Table 2 represent an average for various $\mathrm{C}$ and $\mathrm{N}$ contents [9].

The diffusion coefficients, which follow from eqs. 7, are compared in Figs. 3a, b with data from literature. The large crosses with the solid line are calculated with eq. (7a) for octahedral diffusion. These data are compared with that of the Snoek relaxation from literature and from high temperature diffusion experiments. The majority of these data is from a compilation of Lord and Beshers [11]. Alternatively, the dashed line represents the tetrahedral diffusion (eq. $7 \mathrm{~b}$ ). Figs. $3 \mathrm{a}$ and $3 \mathrm{~b}$ show that the data from internal friction measurements may be well represented by the linear Arrhenius relation over a wide range of $D$ (or $\tau)$-values ( 8 to 10 decades). The diffusion data fit better to octahedral diffusion.

Deviations from ideal Arrhenius behaviour can be seen on Figs. 3a and $3 b$ for higher and lower temperatures. The high temperature diffusion data of $\mathrm{Fe}-\mathrm{C}$ show a deviation from ideal Arrhenius behaviour in the temperature range of the magnetic phase transition $\left(\mathrm{T}_{\mathrm{c}}\right)$. For low temperatures, the data represented by hatched symbols were obtained with mechanical and magnetic after-effect experiments. These data from earlier years (1950 - 1961) suffer from two experimental shortcomings: (i) The mechanical after-effect experiments were carried out without application of a magnetic field, which is necessary for suppression 

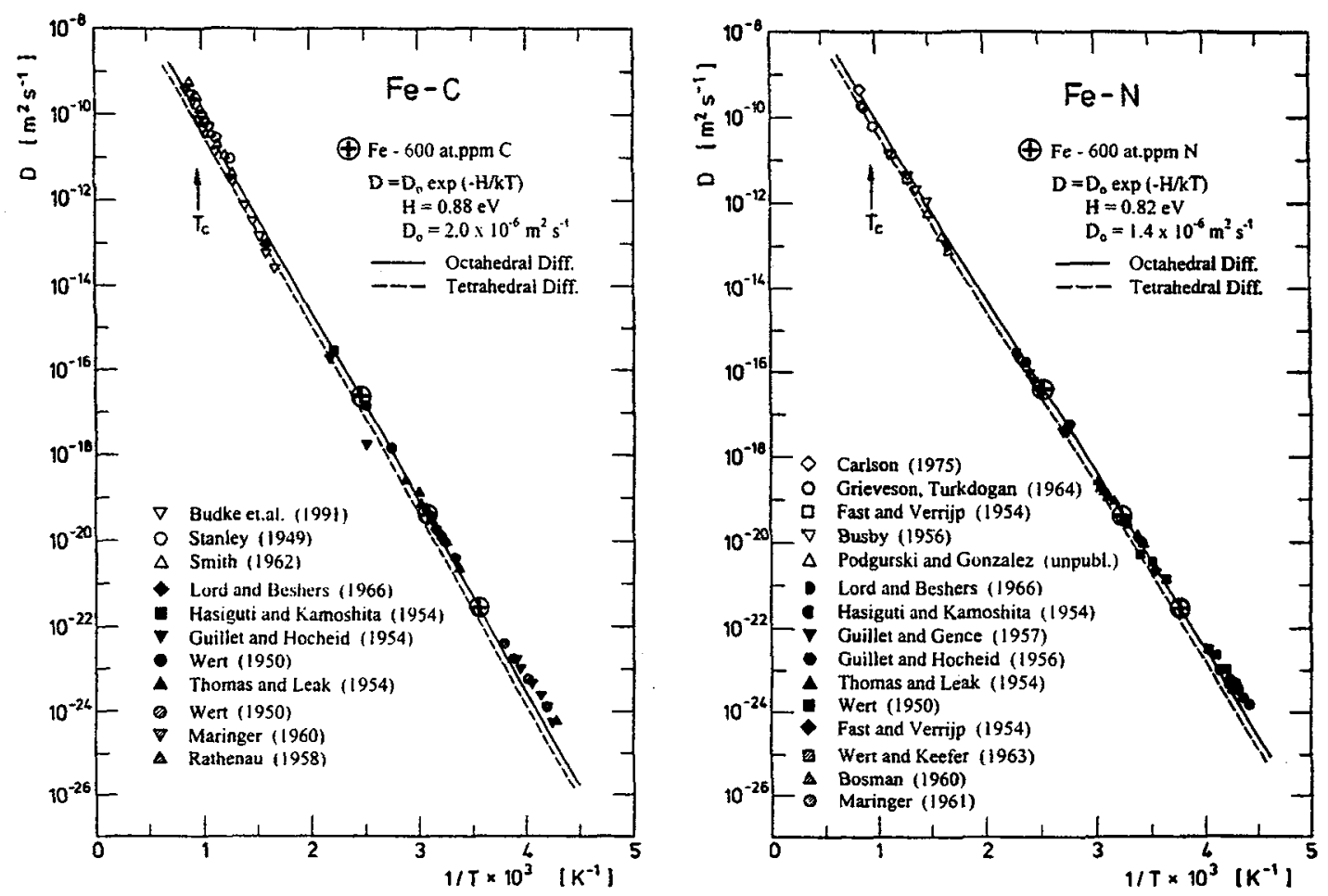

Figure 3: Arrhenius plot of the diffusion coefficient in (a) $\mathrm{Fe}-\mathrm{C}$ and (b) $\mathrm{Fe}-\mathrm{N}$.

Compilation of Snoek relaxation data and high temperature diffusion data.

of the magnetoelastic relaxation. (ii) Interaction of the interstitial solute atoms at higher interstitial contents does not allow to analyse the after-effect curves with a single relaxation time [12]. Both reasons may explain the deviation from the linear Arrhenius relationship. Mc Lellan et al. [13-15] included these questionable after effect data in their analysis by applying a nonlinear polynomial fit. They concluded on a nonlinear Arrhenius behaviour over the whole temperature range. This evaluation also gives too low values for the activation enthalpy of $\mathrm{Fe}-\mathrm{C}$ and $\mathrm{Fe}-\mathrm{N}$.

\subsection{Relaxation Strength}

\subsubsection{Polycrystals}

The relaxation strength in a polycrystal represents an average over all grains. A rigorous theoretical calculation is not possible - even if data on single crystals are available - because of averaging problems (texture, boundary conditions) [3]. However, even with polycrystals the Snoek Relaxation can be used as an analytical method, by using specimens having the same grain size and texture and calibrating the relaxation for various interstitial contents. For a given species of interstitial, the relaxation strength $\Delta$ is (according to eqs. IVa, IVb) proportional to the concentration $\mathrm{c}_{0}$ :

$$
\mathrm{Q}_{\mathrm{m}}^{-1} \equiv \Delta / 2=\mathrm{A} \cdot \mathrm{c}_{\mathrm{o}}
$$

The factor $A=Q_{m}^{-1} / c_{o}$ can be determined empirically by calibration with other methods, e.g. chemical analysis and/or electrical resistivity. This procedure has been demonstrated for O-doped wires of ultrahigh purity $\mathrm{Nb}$ for a wide range of $\mathrm{O}$ concentrations [17]. The experimental results are shown on Fig 4. As can be seen, the proportionality between $Q^{-1}$ and $c_{o}$ is valid for a wide range of concentrations between about 20 up to 10000 at.ppm oxygen corresponding to $A=4.8_{1} \cdot 10^{-6}$ at.ppm ${ }^{-1}$. In a similar way, the 
Snoek peak of $\mathrm{Fe}-\mathrm{C}$ and $\mathrm{Fe}-\mathrm{N}$ has been calibrated by combination of chemical analysis and magnetic after-effect measurements [18, 19].

Snoek-peak measurements are widely applied as a nondestructive analytical method. Numerous applications exist for solubility and precipitation studies $[3,16]$. The sensitivity allows detection of small interstitial contents in the ppm range. Fig. 5 gives an example of a Snoek peak measurement of an iron wire which contains 20 at.ppm carbon in interstitial solution. The detection limit in this case is in the range of 1 at.ppm. Another example for detection of small amounts of carbon in $\mathrm{Fe}-\mathrm{Ni}$ meteorites is given in another paper of this conference [20].

\subsubsection{Single Crystals}

According to Table 1 (eqs. Ib and IVb), the relaxation strength for tetragonal dipoles under torsional oscillations is

$$
\Delta=\frac{\delta \mathrm{G}^{-1}}{\mathrm{G}^{-1}}=\frac{4 \mathrm{c}_{0} \mathrm{v}_{0}}{3 \mathrm{kT}}\left(\lambda_{1}-\lambda_{2}\right)^{2} \mathrm{~F}(\Gamma)
$$

Measurements on single crystals allow determination of the dipole shape factor $\delta \lambda=\left|\lambda_{1}-\lambda_{2}\right|$ if the concentration of the interstitial atoms $c_{0}$ is known. Since $\left(\lambda_{1}-\lambda_{2}\right)$ enters quadratically in eq. (9), only the magnitude, but not the sign, can be obtained. In recent experiments, the $\lambda$-tensor of $\mathrm{O}$ and $\mathrm{N}$ in $\mathrm{Nb}$ and $\mathrm{Ta}$ crystals was determined [8]. The specimens were prepared from ultrapure metals, with $\mathrm{O}$ or $\mathrm{N}$ doping in pure $\mathrm{O}_{2}$ or $\mathrm{N}_{2}$, after careful decarburizing and degassing (for details of sample preparation see [17, 21]). The interstitial contents were determined in each case by chemical analysis and electrical resistivity measurements. The results of the measurements are shown in Fig. 6 for Nb-O and Nb-N, and in Fig. 7 for Ta-O and Ta-N. The following $\left|\lambda_{1}-\lambda_{2}\right|$-values result from these experiments:

Table 3: Shape factor $\left|\lambda_{1}-\lambda_{2}\right|$ of $\mathrm{O}$ and $\mathrm{N}$ in $\mathrm{Nb}$ and Ta.

\begin{tabular}{c|c|c|c|c}
\hline & $\mathrm{Nb}-\mathrm{O}$ & $\mathrm{Nb}-\mathrm{N}$ & $\mathrm{Ta}-\mathrm{O}$ & $\mathrm{Ta} \mathrm{N}$ \\
\hline$\left|\lambda_{1}-\lambda_{2}\right|$ & $0.61 \pm 0.01$ & $0.65 \pm 0.01$ & $0.67 \pm 0.02$ & $0.70 \pm 0.02$ \\
\hline
\end{tabular}

The value for $\mathrm{Nb}-\mathrm{O}$ represents an average from 3 crystals (see also Fig. 6), that for Ta-O from 2 crystals. Comparison of the dipole shape factors for $\mathrm{Nb}$ and $\mathrm{Ta}$ shows that oxygen exhibits in both cases a smaller value than nitrogen, as may be expected from size considerations. The $\left|\lambda_{1}-\lambda_{2}\right|$ values in $\mathrm{Ta}$ are about $10 \%$ larger than in $\mathrm{Nb}$. Furthermore, the orientation dependence of the relaxation amplitude was examined for $\mathrm{O}$ doped $\mathrm{Nb}$ crystals with various orientations, [100] $(\Gamma=0),[110](\Gamma=0.25)$ and [111] $(\Gamma=0.33)$. The results are depicted in Fig. 8. Since crystals with various $O$ contents were examined, the quantity $\delta \mathrm{G}^{-1} / \mathrm{c}_{0}$ is plotted as a function of $\Gamma$. The expected relation for tetragonal dipoles (Fig. la and eq. 9 ), i.e. of $\delta G^{-1} / c_{0} \propto \Gamma$, is confirmed by these experiments.

\section{DEFECTS IN CUBIC STABILIZED $\mathrm{ZrO}_{2}$}

Oxides which possess the cubic fluorite structure, such as $\mathrm{ZrO}_{2}, \mathrm{CeO}_{2}$, and $\mathrm{ThO}_{2}$, when doped with lower valent cations (e.g. $\mathrm{Y}^{3+}, \mathrm{Ca}^{2+}$ ), form oxygen vacancies as charge compensating defects (for a recent review see [22]). At high temperatures, migration of oxygen ions via the vacancies is the reason for the superb ionic conduction of these ionic crystals. At low temperatures, the positively-charged oxygen vacancies are associated with the lower valent, negatively-charged dopant cations due to Coulomb interaction. These associates represent elastic and electric dipoles. For the case of doped $\mathrm{ThO}_{2}$ [23] and $\mathrm{CeO}_{2}$ [24], it was demonstrated that these complexes are correlated with mechanical and dielectric loss peaks. Wachtman and Nowick and co-workers $[23,24]$ proposed an atomic model, in which the oxygen vacancies are positioned on the 8 nearest neighbour sites around the dopant cations. For this defect model, the theory of anelastic and dielectric relaxation [2] predicts that the relaxation times for anelastic and dielectric relaxation differ by a factor of two [25]. This was confirmed by experiments on $\mathrm{CeO}_{2}$ and $\mathrm{ThO}_{2}$. 


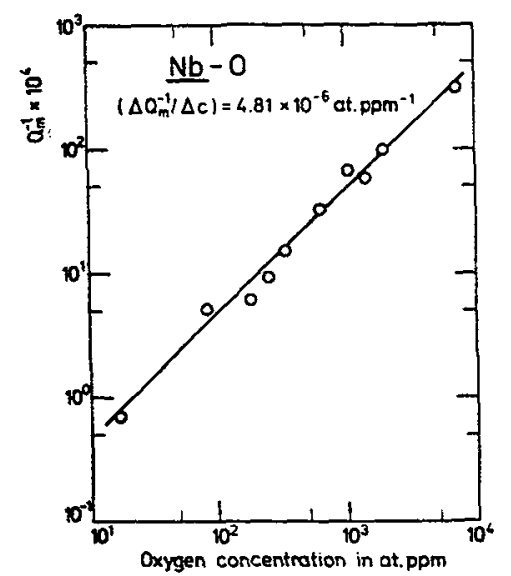

Figure 4: Concentration dependence of the Snoek peak heights in $\mathrm{Nb}$ doped with various $\mathrm{O}$ contents.

a)

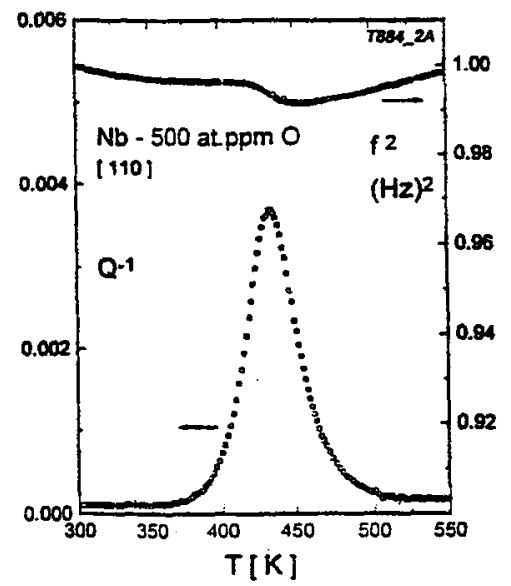

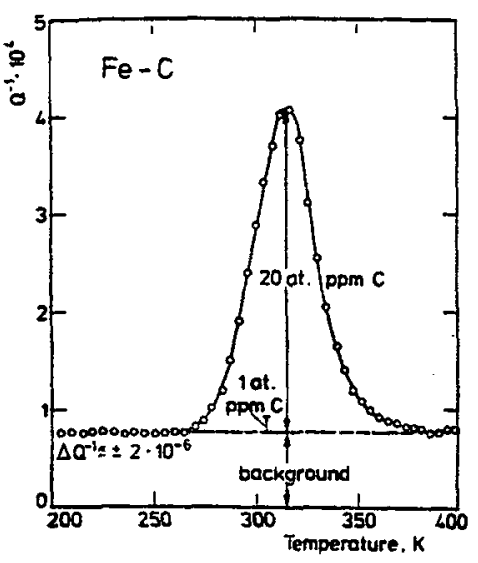

Figure 5: Snoek peak in Fe-C with 20 at.ppm C.

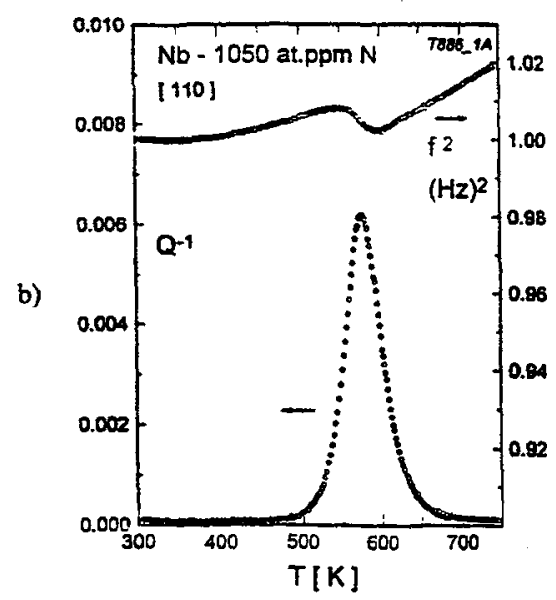

Figure 6: $Q^{-1}$ and $\mathrm{f}^{2} / \mathrm{f}^{2}{ }_{300 \mathrm{~K}}$ as a function of temperature for [110] oriented $\mathrm{Nb}$ single crystals. (a) Doped with 500 at.ppm $\mathrm{O}$ (f $\approx 3 \mathrm{~Hz}$ ). (b) Doped with 1050 at.ppm N $(\mathrm{f} \approx 2.4 \mathrm{~Hz})$.
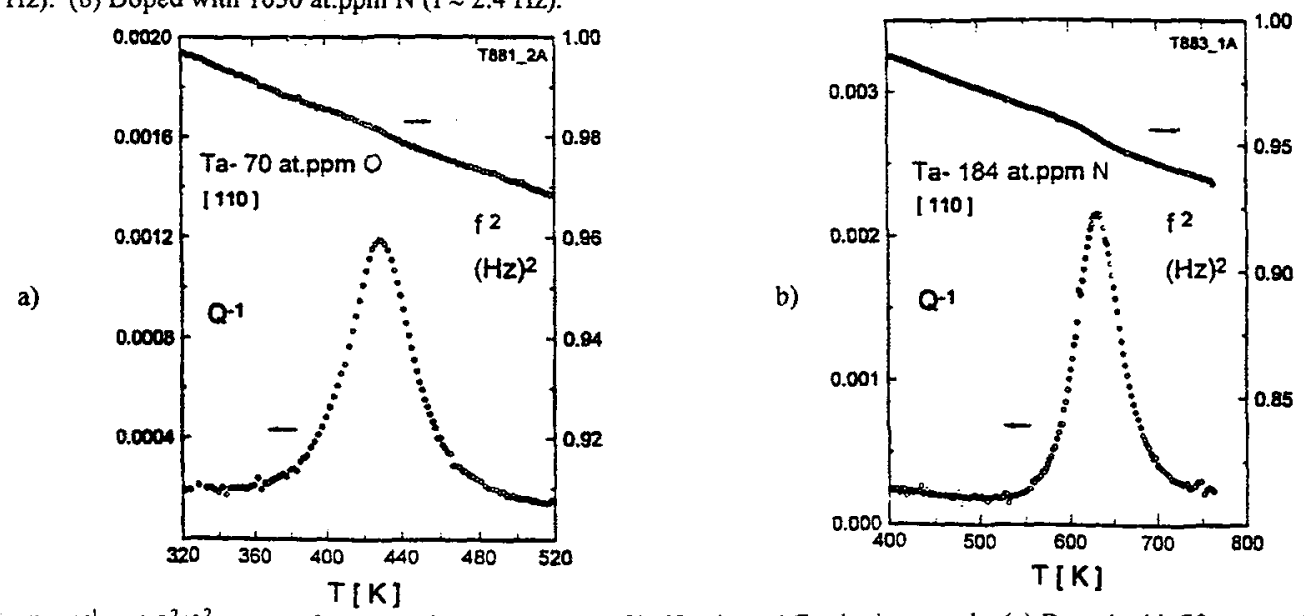

Figure 7: $Q^{-1}$ and $\mathrm{f}^{2} / \mathrm{f}^{2} 300 \mathrm{~K}$ as a function of temperature for [110] oriented Ta single crystals. (a) Doped with 70 at.ppm $\mathrm{O}$ (f $\approx 3 \mathrm{~Hz}$ ). (b) Doped with 184 at.ppm N $(\mathrm{f} \approx 3 \mathrm{~Hz}$ ). 


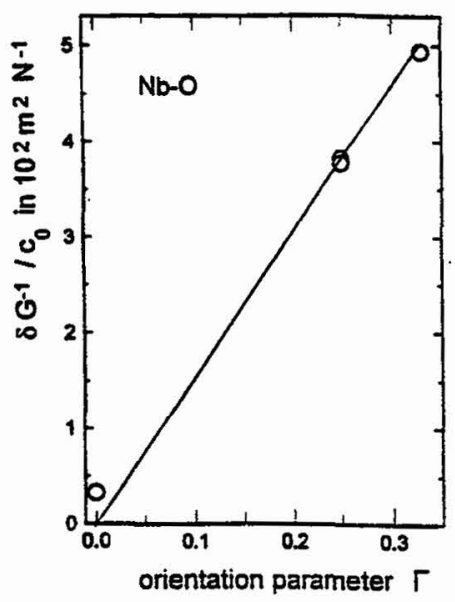

Figure 8: Variation of $\delta G^{-1} / c_{0}$ with orientation parameter $\Gamma$ in $\mathrm{Nb}-\mathrm{O}$.

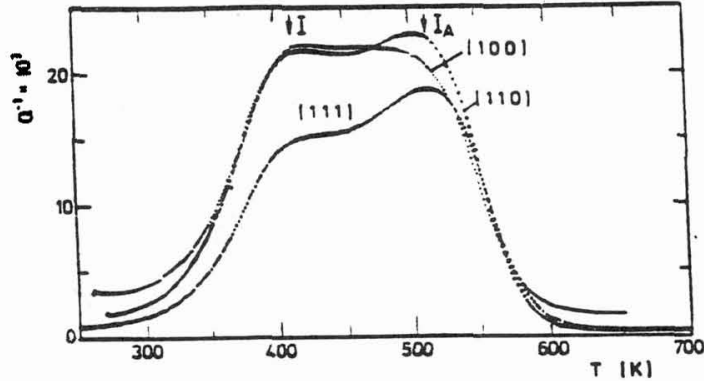

a)

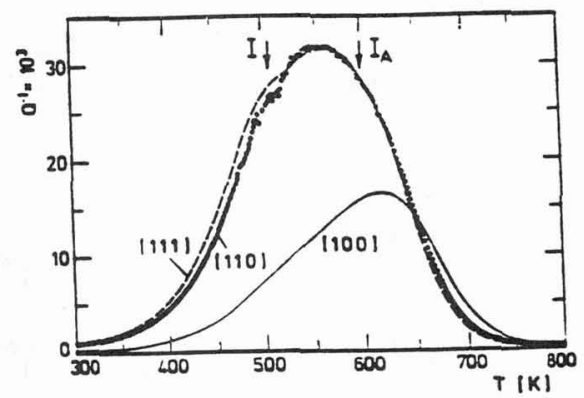

b)

Figure 9: $\mathrm{Q}^{-1}$ vs. $\mathrm{T}$ of $\mathrm{Y}_{2} \mathrm{O}_{3}$ stabilized $\mathrm{ZrO}_{2}$ for different crystal orientations, (a) Torsional oscillations, $\mathrm{f} \approx 3 \mathrm{~Hz}$, (b) Flexure oscillations, $\mathrm{f} \approx 3 \mathrm{kHz}$.

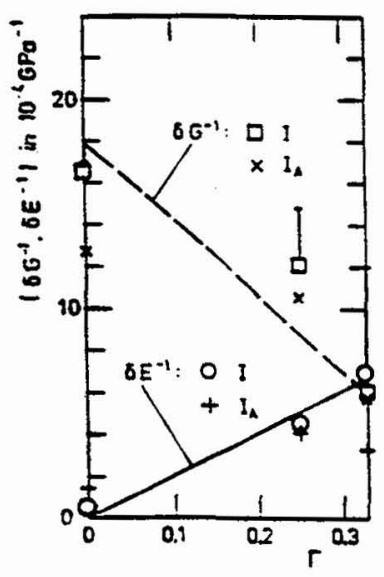

Figure 10: Variation of relaxation amplitudes $\delta E^{-1}$ and $\delta G^{-1}$ of submaxima $I$ and $I_{A}$ in $\mathrm{ZrO}_{2}-10 \mathrm{~mol} \% \mathrm{Y}_{2} \mathrm{O}_{3}$. a)

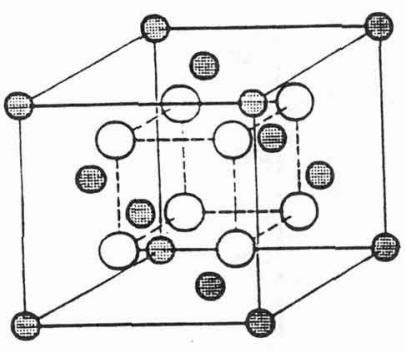

cation
$0 . \bigcirc$ anion (oxygen) b)

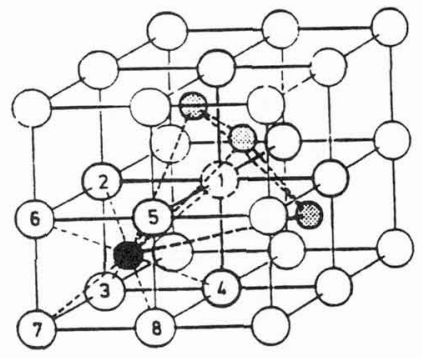

dopant cation (Y.Ca)

(T) oxygen vacancy
Figure 11: Fluorite structure in two representations to demonstrate the coordination around the cations (a) and anions (b). The oxygen vacancy-cation complex with 8 nearest neighbour sites is shown in (b). 
Later experiments on $\mathrm{ZrO}_{2}$ [26] showed that this ratio is also close to two for yttria doped tetragonal zirconia $3 \mathrm{Y}$-TZP which exhibits a slightly distorted cubic lattice with tetragonality $\mathrm{c} / \mathrm{a}=1.02$.

Direct evidence for the eight position model would come from experiments that show that the dipoles exhibit trigonal symmetry [25]. For these experiments, single crystals with different cristallographic orientations are required. Crystals of cubic stabilized zirconia of sufficient size have recently become available. The experimental results [27] are presented in the following.

Fig. 9a shows results of measurements on single crystals with three different orientations of the longitudinal axis [100], [110], [111] with torsional oscillations $(\approx 3 \mathrm{~Hz})$. The specimens (dimensions $40 \times 5 \times 1 \mathrm{~mm}^{3}$ ) were cut from a $\mathrm{ZrO}_{2}-10 \mathrm{~mol} \% \mathrm{Y}_{2} \mathrm{O}_{3}$ crystal [26]. Results obtained with flexure oscillations are depicted in Fig. $9 \mathrm{~b}(\approx 3 \mathrm{kHz})$. Both the low frequency and high frequency measurements show a prominent loss maximum between 400 and $600 \mathrm{~K}$. Obviously, the maximum is composed of two overlapping maxima which are designated as $I$ and $I_{A}$. Maximum $I$ corresponds to the one and only maximum which is present in tetragonal zirconia [26]. The height of the maxima varies with the orientation of the longitudinal axis. The loss spectra as represented in Figs. 9a and b were decomposed into two broadened Debye Maxima $\left(I, I_{A}\right)$ assuming a lognormal distribution of relaxation times [27]. The relaxation amplitudes, $\delta \mathrm{E}^{-1}$ and $\delta \mathrm{G}^{-1}$, were determined for each peak from the peak heights, according to equations I-III in Table 1. The variation of the relaxation amplitudes with the orientation parameter $\Gamma$ is shown in Fig. 10. Comparison with Figure 1 indicates that the orientation dependence of peak $I$ is consistent with a trigonal defect symmetry (Fig. 1b). Maximum $I_{A}$ does not exhibit a linear relation between either $\delta E^{-1}$ and $\delta G^{-1}$ and $\Gamma$, as would be expected for simple atomic defects in cubic crystals. This indicates that defects of lower symmetry and/or interaction of defects (agglomerates) may contribute to this relaxation.

The atomic defect model for peak $I$ is presented in Fig. 11. Fig. 11a shows the fluorite lattice with fcc packing of the cations and the oxygen ions inside. The simple cubic packing of the oxygen ions (with a cation in every second cube) is depicted in Fig. 11b. An oxygen vacancy is placed in the centre of the unit cell. Inspection of Fig. $11 \mathrm{~b}$ shows that an isolated oxygen vacancy in the fluorite lattice represents an isotropic point defect with cubic symmetry which does not contribute to anelastic relaxation. In Fig. 11 the oxygen vacancy is located at a nearest neighbour position to the dopant ion $(\mathrm{Y}, \mathrm{Ca})$ and constitutes an elastic (and electric) dipole. Reorientation of the dipole may occur by jumping of the vacancy around the dopant iron over the 8 nearest neighbour sites as indicated. The experiments confirm that the dipole represents a point defect with trigonal $(<111>)$ symmetry. In cubic $\mathrm{CaO}(\approx 12 \mathrm{~mol} \%)$-stabilized $\mathrm{ZrO}_{2}$, only one loss peak is present [28]. This peak is almost absent in flexure oscillations for a [100] oriented crystal, thus confirming also for $\mathrm{CaO}$-doped $\mathrm{ZrO}_{2}$ the trigonal defect symmetry.

\section{CONCLUSIONS AND PERSPECTIVES}

Two examples for anelastic relaxation of point defects in cubic crystals are presented:

Measurements of the Snoek relaxation of heavy interstitial solute atoms $(\mathrm{O}, \mathrm{N}, \mathrm{C})$ in bcc metals (e.g. Fe, $\mathrm{Nb}, \mathrm{Ta}$ ) allow determination of interstitial contents down to a few at.ppm. From experiments with single crystals, the dipole shape factor $\left|\lambda_{1}-\lambda_{2}\right|$ is determined for $\mathrm{O}$ and $\mathrm{N}$ in $\mathrm{Nb}$ and Ta. The tetragonal symmetry of the interstitials is confirmed by experiments on $\mathrm{Nb}-\mathrm{O}$ crystals with various orientations. Internal friction measurements on $\mathrm{Fe}-\mathrm{C}$ and $\mathrm{Fe}-\mathrm{N}$, carried out over a wide range of frequency, indicate that interstitial diffusion occurs via octahedral sites.

$\mathrm{ZrO}_{2}$, which possesses the cubic fluorite structure when doped with lower valent cations, contains point defects created for charge compensation. Experiments on $\mathrm{ZrO}_{2}-10 \mathrm{~mol} \% \mathrm{Y}_{2} \mathrm{O}_{3}$ and $\mathrm{ZrO}_{2}-12 \mathrm{~mol} \% \mathrm{CaO}$ single crystals allow identification of the point defects. These consist of associates of dopant cations and oxygen vacancies on nearest neighbour sites, representing elastic (and electric) dipoles with trigonal $(<111>)$ symmetry.

The utility of mechanical spectroscopy for the study of point defects is demonstrated in further contributions to this conference: (i) In cubic $\mathrm{ZrO}_{2}-\mathrm{Y}_{2} \mathrm{O}_{3}$ the broadening of peaks $\mathrm{I}$ and $\mathrm{I}_{\mathrm{A}}$ (Figs. 9a and b) is apparently due to interaction between the dipoles. This interaction is analysed by applying the coupling 
model [32]. (ii) Experiments on Al-Pd-Mn quasicrystals show a loss maximum at $\approx 350 \mathrm{~K}$ with an attempt frequency $\tau_{\infty}^{-1} \approx 10^{14} \mathrm{~s}^{-1}$ characteristic for point defect relaxations [33]. This peak is assigned to a new type of "point" defect present in quasicrystals, the phasons. Quasicrystals represent a new state of condensed matter, which exhibits long-range quasiperiodic translational order and orientational order with disallowed symmetry (e.g. five-fold). Phasons are imperfections in an ideal arrangement of tiles (Penrose lattice) which are produced by violation of matching rules. Anelastic relaxation may occur by phason flips [33] corresponding to (local) atomic jumps.

Acknowledgements. The author is indebted to the Deutsche Forschungsgemeinschaft for financial support.

\section{References}

[1] Snoek, J.L., Physica (Utrecht) 8 (1941) 711-733.

[2] Nowick, A.S., and Heller, W.R., Adv. Phys. 14 (1965) 101-166.

[3] Nowick, A.S. and Berry, B.S., Anelastic Relaxation in Crystalline Solids (Academic Press, New York, 1972).

[4] De Batist, R., Internal Friction of Structural Defects in Solids (North Holland, Amsterdam, 1972).

[5] Weller, M., Li, G.Y., Zhang, J. X., Kê, T.S., and Diehl, J., Acta Metall. 29 (1981) 1047-1054.

[6] Seeger, A., Weller, M., Diehl, J., Pan, Z.L., Zhang, J.X., Kê, T.S., Z. Metallkde. 73, (1982) 1-20.

[7] Weller, M., J. de Physique 46, C10 (1985) 7-14.

[8] Weller, M., J. de Physique IV, 5, C7 (1995) 199-204.

[9] Weller, M., Proc. "High Nitrogen Steels", Varna, Bulgaria, Oct. 1989, 1991 40-42 and 194-195.

[10] Weller, M., "Nichtmetalle in Metallen '96" (U. Hirschfeld, D., ed., DGM Informationsgesellschaft, Oberursel 1996), 161-170.

[11] Lord, A.E., and Beshers, D.N., Acta Metall. 14 (1966) 1659-1672.

[12] Haneczok, G., Weller, M., and Diehl, J., Mater.Sci Forum 119-121 (1993) 101-106.

[13] Da Silva, J.R.G., Mc Lellan, R.B., Mater.Sci. Eng. 26 (1976) 83-87.

[14] Mc Lellan, R.B. and Wasz, M.L., J. Phys. Chem. Solids 54 (1993) 583-586.

[15] Wasz, M.L. and Mc Lellan, R.B., Scripta Metall. 28 (1993) 1461-1463.

[16] Fast, J.D., "Gases in Metals" (The Macmillan Press Ltd., London and Basingstoke, 1976).

[17] Schuize, K., Grallath, E., and Weller, M., Z. Metallkde 72 (1981) 439-444.

[18] Hirscher, M., Walz, F., and Weller, M., J. de Physique IV, 5, C7 (1995) 175-180.

[19] Walz, F., Weller, M., and Hirscher, M., phys.stat.sol. 154 (1996) 765-778.

[20] Weller, M., and Wert, C., Snoek peaks of Carbon in Fe-Ni Meteorites, this conference.

[21] Fromm, E., Gebhardt, E., Gase und Kohlenstoff in Metallen (Springer Verlag, Berlin, etc. 1976).

[22] Weller, M., "Defects in Oxide Ceramics and Their Characterization", Parts I and II, J. of Mater. Educ. 17 (1995), 1-32 and 33-77.

[23] Wachtmann, J.B., Phys.Rev. 131 (1963) 517.

[24] Andersen, M.P., and Nowick, A.S., J. de Physique 42, C5 (1981) 823-828.

[25] Nowick, A.S., in: Diffusion in Crystalline Solids (G.E. Murch and A.S. Nowick eds., Academic Press N.Y., 1984) p. 143-188.

[26] Weller, M., and Schubert, H., J. Am. Ceram. Soc. 69 (1986) 573-577.

[27] Weller, M., Z. Metallkde. 84 (1993) 381-386.

[28] Weller, M., Proc. of the 17th Ris $\phi$ Int. Symposium on Materials Science: High temperature Electrochemistry: Ceramics and Metals. (Eds. F.W. Poulsen et al., Riso National Laboratory, Roskilde, Denmark, 1996) p. 485-490.

[29] Haneczok, G., Poloczek, T., and Moron, J.W. J. Less. Comm. Met. 98 (1984) 33-44.

[30] Klein, M.J., J. Appl. Phys. 38 (1967) 167-170.

[31] Boratto, F.J.M., Reed-Hill, R.E., Scripta Metall. 11, (1977) 1107-1111.

[32] Haneczok, G., and M. Weller, this conference.

[33] Weller, M., Feuerbacher, M., Diehl, J., and Urban, K., this conference. 